\title{
What are the limits on whale ear bone size? Non-isometric scaling of the cetacean bulla
}

\author{
Sabrina L Groves ${ }^{\text {Corresp., } 1,2}$, Carlos Mauricio Peredo ${ }^{1,3,4}$, Nicholas D Pyenson ${ }^{1,5}$ \\ ${ }^{1}$ Department of Paleobiology, National Museum of Natural History, Washington D.C., District of Columbia, United States \\ 2 Department of Biological Sciences, Mount Holyoke College, South Hadley, MA, United States \\ 3 Department of Earth and Environmental Science, University of Michigan - Ann Arbor, Ann Arbor, Michigan, United States \\ 4 Department of Marine Biology, Texas A\&M University - Galveston, Galveston, Texas, United States \\ 5 Department of Paleontology and Geology, Burke Museum of Natural History and Culture, Seattle, Washington, United States \\ Corresponding Author: Sabrina L Groves \\ Email address: grove23s@mtholyoke.edu
}

The history of cetaceans demonstrates dramatic macroevolutionary changes that have aided their transformation from terrestrial to obligate aquatic mammals. Their fossil record shows extensive anatomical modifications that facilitate life in a marine environment. To better understand the constraints on this transition, we examined the physical dimensions of the bony auditory complex, in relation to body size, for both living and extinct cetaceans. We compared the dimensions of the tympanic bulla, a conch-shaped ear bone unique to cetaceans, with bizygomatic width-a proxy for cetacean body size. Our results demonstrate that cetacean ears scale non-isometrically with body size, with about $70 \%$ of variation explained by increases in bizygomatic width. Our results, which encompass the breadth of the whale fossil record, size diversity, and taxonomic distribution, suggest that functional auditory capacity is constrained by congruent factors related to cranial morphology, as opposed to allometrically scaling with body size. 
1 What are the limits on whale ear bone size? Non2 isometric scaling of the cetacean bulla

3 Sabrina L. Groves ${ }^{1,2 *}$, Carlos Mauricio Peredo ${ }^{1,3,4}$, Nicholas D. Pyenson ${ }^{1,5}$

$5 \quad{ }^{1}$ Department of Paleobiology, National Museum of Natural History, Washington D.C.

$6 \quad{ }^{2}$ Department of Biological Sciences, Mount Holyoke College, South Hadley, Massachusetts

7 ' ${ }^{3}$ Department of Earth and Environmental Science, University of Michigan - Ann Arbor, Ann

8 Arbor, Michigan

$9 \quad{ }^{4}$ Department of Marine Biology, Texas A\&M University - Galveston, Galveston, Texas

10 5epartment of Paleontology and Geology, Burke Museum of Natural History and Culture,

11 Seattle, Washington

12

*Corresponding Author:

S.L. Groves

grove23s@mtholyoke.edu

\section{Abstract}

The history of cetaceans demonstrates dramatic macroevolutionary changes that have aided their transformation from terrestrial to obligate aquatic mammals. Their fossil record shows extensive anatomical modifications that facilitate life in a marine environment. To better understand the constraints on this transition, we examined the physical dimensions of the bony auditory complex, in relation to body size, for both living and extinct cetaceans. We compared the dimensions of the tympanic bulla, a conch-shaped ear bone unique to cetaceans, with bizygomatic width - a proxy for cetacean body size. Our results demonstrate that cetacean ears scale non-isometrically with body size, with about $70 \%$ of variation explained by increases in bizygomatic width. Our results, which encompass the breadth of the whale fossil record, size diversity, and taxonomic distribution, suggest that functional auditory capacity is constrained by congruent factors related to cranial morphology, as opposed to allometrically scaling with body size.

\section{Introduction}

The evolutionary history of cetaceans exhibits dramatic transformations that have facilitated their ecological transition from a terrestrial to an obligate marine lifestyle (Pyenson, 2017; Zimmer, 2011). The cetacean fossil record shows extensive anatomical modifications that allowed for this transition by facilitating communication and navigation underwater. This adaptation to life in the water, from terrestrial ancestry, required surmounting or accommodating physical constraints to the functional challenges for hearing (Nummela et al. 2007; Ketten, 1994). Previous studies have documented allometric patterns associated with precocial growth in the ear bones (i.e., 
tympanoperiotic complex) of living cetaceans, demonstrating that extant cetacean ontogeny is, at least partially, driven by acoustic ecology (Lancaster, 2015; Yamato and Pyenson, 2015; Ekdale, 2015; Thean et al., 2017). This study seeks to understand the allometry of cetacean ear bones across their evolutionary history to elucidate the extent to which acoustic ecology constrains variability in tympanic bulla morphology.

The cetacean auditory system has undergone dramatic modifications associated with at least three major shifts throughout cetacean evolutionary history: (1) the land-to-sea transition; (2) ultrasonic hearing for echolocation; and (3) infrasonic hearing in mysticetes (Thean, 2017; Thewissen \& Williams, 2002; Spoor et al. 2008; Thewissen et al. 2001; Fleischer, 1976; Schevill, 1953). Throughout these changes, cetaceans have maintained a unique auditory structure: the pachyosteoslerotic tympanic bulla. The tympanic bulla's large, dense, conchshaped structure works with the mandibles and soft tissues of the inner ear (e.g., inside the periotic) to detect and isolate sound (Luo and Gingerich, 1999; Cozzi et al. 2015; McCormick et al. 1970). The bulla combines with the periotic to form the tympanoperiotic complex (Mead \& Fordyce, 2009). The tympanoperiotic complex is highly diagnostic for taxonomic and phylogenetic research (Ekdale et al. 2011, 2015), and it is readily preserved in the fossil record, providing a marker of acoustic evolution (Churchill et al., 2016; Park et al., 2016, 2019; Mourlam \& Orliac, 2017; Racicot et al. 2018, 2019). Thus, this anatomical unit is useful for studying allometric patterns in cetacean evolutionary history.

Here, we use a comparative dataset of cetacean tympanic bullae, generated from museum specimens and the published literature, spanning the full range of cetacean body size, to test the extent to which body size drives tympanic bulla size. Previous work has shown that some inner ear structures (specifically the bony labyrinth) are strongly correlated with body mass (Ekdale 2015; Racicot et al. 2016). However, biological systems rarely scale isometrically, and modern whales are seemingly approaching an upper limit on body size (Slater et al. 2017; Goldbogen et al. 2019; Gearty et al. 2018), suggesting osteological and/or ecological constraints on scaling. Our study demonstrates that bullae become proportionally smaller as body size increases. Thedataset relies on accessible, low-cost measurement techniques, and includes fossils spanning all of cetacean evolutionary history, including the earliest semi-aquatic stem cetaceans, and major ecological transitions (Pyenson, 2017). We demonstrate that the scaling of tympanic bullae is positively allometric, non-isometric, and smaller than anticipated at the largest body sizes.

\section{Materials \& Methods}

\section{Anatomical Measurements}

We measured the bizygomatic width (BZW), tympanic bulla length (BL), and tympanic bulla width (BW) of cetacean skulls using handheld calipers $( \pm 1 \mathrm{~mm})$. Bizygomatic width was defined as the maximum distance between the lateral edges of the zygomatic processes and was used as a proxy for cetacean body size (Pyenson \& Sponberg 2011). In the case of incomplete skulls, the bizygomatic width was measured from the lateral edge of one zygomatic process to 
77 the midline and doubled. BL was measured in the dorsal and lateral views from the outer posterior prominence to the edge of the involucral ridge following previous authors and as documented by Tsai \& Fordyce (2015) and references therein. Bulla width was measured in ventral views from the mallear ridge to the involucrum following Tsai \& Fordyce 2015 and Tanaka et al. 2018 (Fig. 1). Where possible, we measured both the right and left bulla and used the mean value in this study. Only complete and intact specimens were included in the final dataset. Other studies have used the periotic, specifically inner ear structures such as the spiral cochlea and the bony labyrinth, to test for changes in acoustic ecology through whale evolutionary history. Here, we elect to focus on the tympanic bulla because it is an external structure that can be measured with minimal resource allocations and because tympanic bullae preserve readily in the fossil record, making it easier to amass a large dataset that can be easily replicated.

Figure 1. 3D models of sample cetacean skulls illustrating the measurements collected for this study, including (A) a stem cetacean (Zygorhiza, USNM PAL 11962), (B) a mysticete (Balaenoptera, USNM VZ 593554), and (C) an odontocete (Tursiops USNM VZ 550969). Specimens are scaled to the same condylobasal length. BZW: Bizygomatic width, measured as the maximum distance across the zygomatic processes of the squamosals or estimated by doubling the measurement to the midline. BL: tympanic bulla length measured along its longest anteroposterior axis following the orientation guidelines of Mead and Fordyce (2009). BW: tympanic bulla width measured along its widest transverse axis following the orientation guidelines of Mead and Fordyce (2009).

\section{Institutional Abbreviations UMMP} University of Michigan Museum of Paleontology, Ann Arbor, Michigan, USA.

\section{USNM}

Departments of Paleobiology and Vertebrate Zoology (Division of Mammals), National Museum of Natural History, Smithsonian Institution, Washington, District of Columbia, USA.

\section{Data Acquisition and Taxonomic Selection}

We measured the bizygomatic width, bulla length, and bulla width for specimens that preserve both skulls and at least one complete tympanic bulla. Our data set includes fossil cetaceans from the UMMP and USNM; we then supplemented this dataset with additional measurements from published specimens from the literature. Juvenile and subadult specimens were excluded as examining ontogenetic growth is beyond the scope of this study. The final dataset (Table S1) includes 267 representatives of nearly every known cetacean taxon $(n=135)$ with pairable bizygomatic widths and tympanic bulla.

\section{Phylogenetic Analysis}

To test for potential phylogenetic signal, we constructed a composite tree using previously established phylogenetic relationships and their heuristic searches with accepted support values (Lambert et al., 2017; Tanka \& Fordyce, 2017; Marx \& Fordyce, 2015; Peredo \& Uhen, 2016; 
117 Gatesy et al. 2012; O'Leary, 2001). The composite matrix, constructed in MESQUITE 3.6

118 (Maddison \& Maddison, 2018), included three new continuous characters: BZW, BL, and BW.

119 Phylogenetic Independent Contrasts (PICs) correlated continuous size variable traits with

120

121

122

123

124

125

126

127

128

129

130

131

132

133

134

135

136

137

138

139

140

141

142

143

144

145

146

147

148

149

150

151

152

153

154

155

corresponding taxa using non-transformed data in PDTREE. Branch lengths were set to 1.0 and colors were allocated by character value (Pyenson et al. 2013). PIC axes were set as follows: Ythe character for exploration $(|\mathrm{BL}: \mathrm{BZW}|)$ and $\mathrm{X}$ - the tree character $(\sqrt{\Sigma \rho(\mathrm{X}, \mathrm{Y})}$, the square root of the sum of the correlated branch lengths). To assess the phylogenetic underpinnings of nonisometric scaling relationships, we regressed the PICs of the continuous character traits and mapped them back onto the original composite tree (Garland \& Ives, 2000; Pyenson et al, 2013). The dataset exhibited a normal distribution and character trait ranges were spread across families.

\section{Results}

\section{Allometry of Cetacean Tympanic Bullae}

Scaling relationships of tympanic bulla length (Fig. 2 A slope $=0.5488 \mathrm{x}, \mathrm{R}^{2}=0.7055$ ) and bulla width (Fig. $2 \mathrm{~B}$ slope $=0.5644 \mathrm{x}, \mathrm{R}^{2}=0.6824$ ) versus bizygomatic width were positively allometric (Fig. 2). This trend suggests that body size is the predominant correlate influencing ear size, with roughly $70 \%$ of the bullae dimensional variation being explained by changes in body size. We used log-transformed plots to display linear regressions across the sample, allowing size extremes to be shown with minimal axis compression (Fig. 2). The smallest cetaceans (e.g., Cephalorhynchus hectori, Pontoporia blainvillei, and Phocoena phocoena) had bullae that were about twice as long as they were wide (BL:BW 1.7-2.2). Conversely, the largest cetaceans (e.g., Eubalaena glacialis, Megaptera novaeangliae, Balaenoptera physalus) exhibited bullae nearly as wide as they were long (BL:BW 1.1-1.7). At smaller body sizes (BZW $<185 \mathrm{~mm})$, the tympanic bulla length was consistently $15-41 \%$ of bizygomatic width. However, at larger body sizes (BZW $>407 \mathrm{~mm}$ ) bulla length was closer to $10 \%$ and as low as $4 \%$ of bizygomatic width in some specimens of Megaptera novaeangliae and Balaenoptera physalus, indicating that tympanic bullae are proportionally smaller at the largest body sizes.

Figure 2. Log-transformed bivariate plot demonstrating allometric changes in bulla size and bizygomatic width: A. Tympanic bulla length versus bizygomatic width. B. Tympanic bulla width versus bizygomatic width. Black dots represent specimens from the amalgamate dataset. Colored lines represent linear regressions. See text for statistical results.

The patterns observed in the cumulative dataset remain consistent within taxonomic groupings (stem cetaceans, odontocetes, and mysticetes). Larger body sizes were correlated with longer tympanic bulla in all three groups (Fig. 3): stem cetaceans (slope $=0.1626 \mathrm{x}, \mathrm{R}^{2}=0.7166$ ), mysticetes (slope $=0.0248 \mathrm{x}, \mathrm{R}^{2}=0.4635$ ), and odontocetes ( patterns were observed for body size and tympanic bulla width in stem cetaceans (slope $=$ $0.0034 \mathrm{x}, \mathrm{R}^{2}=0.7719$ ), mysticetes (slope $=0.0217 \mathrm{x}, \mathrm{R}^{2}=0.4100$ ), and odontocetes (slope $=0.04 \mathrm{x}$, $\left.\mathrm{R}^{2}=0.5293\right)$. 
156

157

158

159

160

161

162

163

164

165

166

167

168

169

170

171

172

173

174

175

176

177

178

179

180

181

182

183

184

185

186

187

188

189

190

191

192

193

Figure 3. Allometric relationships of stem cetaceans, odontocetes, and mysticetes: A. Tympanic bulla length (BL) versus bizygomatic width (BZW). B. Tympanic bulla width (BW) versus bizygomatic width (BZW). Green circles represent stem cetaceans, red correspond with odontocetes, and blue indicate mysticetes. Colored lines represent linear regressions by group.

Within groups, our data demonstrated insignificant linear growth trajectories, with stem cetaceans and odontocetes constrained to the left side of the graph likely as a result of their smaller body sizes, and mysticetes occupying a wide range of ear and body sizes (Fig. 2-3). As a paraphyletic group, stem cetaceans resemble the tympanic bullae size and proportions of odontocetes despite larger body sizes comparable to those of smaller mysticetes (Fig. 3). The composite dataset includes a diverse assortment of bulla and bizygomatic sizes.

Tympanic bullae and bizygomatic width seemingly conform to the same scaling coefficient, regardless of taxonomic grouping (Fig. 2, 3). Our phylogenetic independent contrasts (PIC) yielded no genus-level clustering in both branch proximity and corresponding character traits, indicating that tympanic bulla size is not governed by phylogeny (Fig. S1).

\section{Discussion}

\section{Scaling \& Function}

Tympanic bullae play a fundamental role in cetaceans' abilities to navigate, communicate, and feed within aquatic systems. Our results demonstrate that cetacean bulla dimensions increase in a positively allometric pattern irrespective of taxonomic identity or phylogenetic history. Nonetheless, the largest cetaceans (mysticetes) exhibit disproportionately small tympanic bullae, while small-bodied cetaceans (e.g. Pontoporia, Platanista, phocoenids, and extinct odontocetes such as Olympicetus and Echovenator) exhibit particularly large ears for their body sizes (Fig. 3). These small-bodied odontocetes all retain proportionately large tympanoperiotic complexes, possibly hinting at a lower limit for cetacean bulla size. Notably, the largest cetaceans are all extant (Rosel et al. 2020; Pyenson \& Sponberg, 2011; Vermeij \& Pyenson, 2016; Slater et al., 2017). Whale body size persists near a lower bound for much of their evolutionary history and only reached extreme gigantism during the Plio-Pleistocene (Slater et al. 2017). Such departures from linearity suggest that functional auditory capacity is not based on proportional congruences, but may instead be constrained by functional or biological auditory limits.

One such constraint may be osteological: the tympanic bulla functions by acoustically isolating the hearing apparatus from the rest of the skull (Luo and Gingerich, 1999; Nummela et al. 2004; Cozzi et al. 2015) and it remains unclear how acoustic isolation functions at proportionally larger body sizes. Another potential limitation may be ecological. The pachyosteosclerotic bulla enhances the reception of sound underwater, and may therefore be bound within a functional size range with upper and/or lower limits of effectiveness. This constraint is likely true for echolocating odontocetes, which rely on high frequency sounds not just for communication, but for navigation and feeding as well (Ketten, 1994). Future research is needed to determine how 
194

195

196

197

198

199

200

201

202

203

204

205

206

207

208

209

210

211

212

213

214

215

216

217

218

219

220

221

222

223

224

225

226

227

228

229

230

231

bulla size influences sound reception underwater. Finally, cetaceans often exhibit paedomorphic ear bone morphology at birth (Cozzi et al. 2015; Yamato and Pyenson, 2015), suggesting that future work examining changes in allometry across whale ontogeny may reveal developmental constraints on ear bone scaling. Such studies would necessarily focus on extant sampling, as developmental series are mostly lacking from the fossil record of cetaceans.

\section{Evolutionary Patterns}

Cetaceans underwent major morphological transformations associated with an increasingly marine lifestyle, but our results demonstrate that tympanic bulla allometry remains relatively unchanged throughout 50 million years of cetacean evolutionary history. Stem cetaceans maintain a stronger consistent relationship between tympanic bulla dimensions and body size than either of the crown groups (Fig. 3). This pattern may hold because stem cetaceans exhibit small and medium body sizes overall, but generally not the gigantism observed in extant mysticetes (Fig. 3). Despite innovations that involve hearing, such as ultrasonic echolocation in odontocetes and extreme gigantism in mysticetes, neither extant lineage differs markedly from stem cetaceans in terms of tympanic bullae dimensions and scaling. This result is noteworthy given their seemingly disparate ecologies and suggests little functional selection on tympanic bulla dimensions. Instead, bulla dimensions converge around a common form. The consistency of tympanic bulla dimensions across the land-to-sea transition, even in stem cetaceans, reinforces the hypothesis that even the earliest cetaceans already had aquatic-adapted tympanic bullae (Luo and Gingerich, 1999; Nummela et al. 2004).

Notably, while our study examines the relationship between tympanic bullae size and body size, it does not directly test whether changes in tympanic bulla size are driven by ecological factors. Future studies might test specific ecological factors as potential drivers of bulla size to help elucidate the relationship between ear size and functional ecology. For example, it remains unclear whether bullae can reach substantially larger sizes, or if the observed values in extant whales represent an upper limit, as seems to be the case for body size (Slater et al. 2017). Further study in this regard will reveal to what extent tympanic bulla size and shape are restrained by functional ecology. Recent authors have begun to elucidate the specific mechanism for infrasonic hearing in mysticetes (Park et al 2017, Ekdale et al. 2015), though it remains overall less understood than ultrasonic hearing in odontocetes. Consequently, future work in this area has the potential to inform a potential relationship between mysticete hearing and mysticete gigantism.

\section{Acknowledgements}

We thank David Bohaska, for access to USNM paleobiology specimens, John Ososky and Michael McGowen and for providing access to USNM zoology specimens, and Adam Rountrey for access to UMMP paleobiology and vertebrate zoology specimens. We also thank Sirpa Nummela, an anonymous reviewer, and editor J. G. M. Thewissen for their thoughtful comments on the manuscript. 
232

233

234

235

236

237

238

239

240

241

242

243

244

245

246

247

248

249

250

251

252

253

254

255

256

257

258

259

260

261

262

263

264

\section{Funding}

CMP and NDP were supported by the Remington Kellogg Fund and the Basis Foundation. CMP is further supported by National Science Foundation Award \#1906181 and by the University of Michigan Society of Fellows. The funders had no role in study design, data collection and analysis, decision to publish, or preparation of the manuscript.

\section{Conflict of Interest}

The authors declare they have no conflicts of interest.

\section{Author contributions}

Sabrina L. Groves, Carlos Mauricio Peredo, and Nicholas D. Pyenson conceived and designed the study, performed measurements, analyzed the data, prepared figures and/or tables, and authored or reviewed drafts of the manuscript.

\section{References}

Churchill M, Martinez-Caceres M, de Muizon C, Mnieckowski J, Geisler JH (2016) The origin of high-frequency hearing in whales. Current Biology 26, 2144-2149.

Cozzi B, Podesta M, Vaccaro C, Poggi R, Mazzariol S, Huggenberger S, Zotti A (2015) Precocious ossification of the tympanoperiotic bone in fetal and newborn dolphins: an evolutionary adaptation to the aquatic environment? The Anatomical Record 298, 1294-1300.

Ekdale EG, Berta A, Demere TA (2011) The comparative osteology of the petrotympanic complex (ear region) of the extant baleen whales (cetacea: mysticeti). PLoS ONE 6(6), e21311.

Ekdale EG, Racicot RA (2015) Anatomical evidence for low frequency sensitivity in an archaeocete whale: comparison of the inner ear of Zygorhiza kochii with that of crown Mysticeti. Journal of Anatomy 226, 22-39.

Fleischer G (1976) Hearing in extinct cetaceans as determined by cochlear structure. Journal of Paleontology 50, 133-152.

Garland T, Ives AR (2000) Using the past to predict the present: confidence intervals for regression equations in phylogenetic comparative methods. American Naturalist 155, 346-364.

\section{Gatesy J, Geisler JH, Chang J, Buell C, Berta A, Meredith RW, Springer MS, McGowen} MR (2012) A phylogenetic blueprint for a modern whale. Molecular Phylogenetics and Evolution. 
265 Gearty W, McClain CR, Payne JL (2017) Energetic tradeoffs control the size distribution of 266 aquatic mammals. Proceedings of the National Academy of Sciences of the United States of 267 America 115(16), 4194-4199.

268 Geisler JH, Sanders AE, Luo Z (2005) A new protocetid whale (Cetacea: Archaeoceti) from 269 the late middle Eocene of South Carolina. American Museum Novitates 3480, 1-65.

270 Goldbogen JA, Cade, DE, Wisniewska DM, Potvin J, Segre PS, Savoca MS, Hazen EL, 271 Czapanskiy MF, Kahane-Rapport SR, DeRuiter SL, Gero S, Tonnesen P, Gough WT, 272 Hanson MB, Holt MM, Jensen FH, Simon M, Stimpert AK, Arranz P, Johnston DW, 273 Nowacek DP, Parks SE, Visser F, Friedlaender AS, Tyack PL, Madsen PT, Pyenson ND 274 (2019) Why whales are big but not bigger: Physiological drivers and ecological limits in the age 275 of ocean giants. Science 366(6471), 1367-1372.

276 Ketten DR (1994) Functional analyses of whale ears: adaptations for underwater hearing.

277 Proceedings in Underwater Acoustics 1, 264-270.

278 Lambert O, Bianucci G, de Muizon C (2017) Macroraptorial sperm whales (Cetacea, 279 Odontoceti, Physeteroidea) from the Miocene of Peru. Zoological Journal of the Linnean Society 280 179, 404-474.

Lancaster WC (2015) Precocial development within the tympanoperiotic complex in cetaceans. Marine Mammal Science 31(1), 369-375.

Luo Z, Gingerich PD (1999) Terrestrial Mesonychia to aquatic Cetacea: transformation of the basicranium and evolution of hearing in whales. University of Michigan, Papers on Paleontology 31, 1-98.

Maddison WP, Maddison DR (2018) Mesquite: a modular system for evolutionary analysis. Version 3.6.

Marx FG, Fordyce RE (2015) Baleen boom and bust: a synthesis of mysticete phylogeny, diversity, and disparity. Royal Society Open Science 2, 140434.

McCormick JG, Wever EG, Palin J (1970) Sound conduction in the dolphin ear. The Journal of the Acoustic Society of America 48(6), 1418-1428.

Mead JG, Fordyce RE (2009) The therian skull: a lexicon with emphasis on the odontocetes. Smithsonian Contributions to Zoology 627, 1-249.

Mourlam MJ, Orliac MJ (2017) Infrasonic and ultrasonic hearing evolved after the emergence of modern whales. Current Biology 27, 1776-1781.

296 Nummela S, Thewissen JGM, Bajpai S, Hussain ST, Kumar K (2004) Eocene evolution of 297 whale hearing. Nature 430, 776-778. 
Nummela S, Thewissen JGM, Bajpai S, Hussain T, Kumar K (2007) Sound transmission in archaic and modern whales: anatomical adaptations for underwater hearing. The Anatomical Record 290, 716-733.

O'Leary MA (2001) The phylogenetic position of cetaceans: further combined data analyses, comparisons with the stratigraphic record and the discussion of character optimization. American Zoologist 41, 487-506.

Park T, Evans AR, Gallagher SJ, Fitzgerald EMG (2017) Low-frequency hearing preceded the evolution of giant body size and filter feeding in baleen whales. Proceedings of the Royal Society B 284, 20162528.

Park T, Fitzgerald EMG, Evans AR (2016) Ultrasonic hearing and echolocation in the earliest toothed whales. Biology Letters 12, 20160060.

Park T, Mennecart B, Costeur L, Grohe C, Cooper N (2019) Convergent evolution in toothed whale cochleae. BMC Evolutionary Biology 19(195), 1-11.

Peredo CM, Pyenson ND, Marshall CD, Uhen MD (2018) Tooth loss precedes the origin of baleen in whales, Current Biology 28, 1-9.

Peredo CM, Uhen MD (2016) A new basal chaeomysticete (Mammalia: Cetacea) from the Late Oligocene Pysht Formation of Washington, USA. Papers in Palaeontology 2(4), 533-554.

Peredo CM, Uhen MD, Nelson MD (2018) A new kentriodontid (Cetacea: Odontoceti) from the early Miocene Astoria Formation and a revision of the stem delphinidan family Kentriodontidae. Journal of Vertebrate Paleontology, e1411357.

Pyenson ND (2017) The ecological rise of whales chronicled by the fossil record. Current Biology 27, R558-R564.

Pyenson ND, Goldbogen JA, Shadwick RE (2013) Mandible allometry in extant and fossil Balaenopteridae (Cetacea: Mammalia): the largest vertebrate skeletal element and its role in rorqual lunge feeding. Biological Journal of the Linnean Society 108, 586-599.

Racicot RA, Darroch SAF, Kohno N (2018) Neuroanatomy an inner ear labyrinths of the narwhal, Monodon monoceros, and beluga, Delphinapterus leucas (Cetacea: Monodontidae). Journal of Anatomy 233(4), 421-439.

Racicot RA, Gearty W, Kohno N, Flynn JJ (2016) Comparative anatomy of the bony labryrinth of extant and extinct porpoises (Cetacea: Phocoenidae). Biological Journal of the Linnean Society 119(4), 831-846.

Racicot RA, Boessnecker RW, Darroch SAF, Geisler JH (2019) Evidence for convergent evolution of ultrasonic hearing in toothed whales (cetacea: odontoceti). Biology Letters 15, 
20190083.

Ritsche IS, Fahlke JM, Wieder F, Andre H, Manke I, Hampe O (2018) Relationships of cochlear coiling shape and hearing frequencies in cetaceans, and the occurrence of infrasonic hearing in Miocene Mysticeti. Fossil Record 21, 33-45.

\section{Rosel PE, Archer FI, Baker SC, Boness, DJ, Brownell RL, Churchill M, Costa AP,} Domning DP, Fordyce RE, Jefferson TA, Kinze C, Oliveira LR, Perrin WF, Wang JY, Yamada TK (2020) Society for Marine Mammalogy Committee: Taxonomy List. The Society for Marine Mammalogy.

Schevill WE, McBride AF (1953) Evidence for echolocation by cetaceans. Deep Sea Research 3(2), 153-154.

Slater GJ, Goldbogen JA, Pyenson ND (2017). Independent evolution of baleen whale gigantism linked to Plio-Pleistocene ocean dynamics. Proceedings of the Royal Society of Biology 284, 20170546.

Solis-Añorve A, González-Barbaa G, Hernández-Riverab R (2019) Description of a new toothed mysticete from the Late Oligocene of San Juan de La Costa, B.C.S., México. Journal of South American Earth Sciences 89, 337-346.

Spoor F, Thewissen JGM (2008) Comparative and functional anatomy of balance in aquatic mammals. Sensory Evolution on the Threshold: Adaptations in Secondary Aquatic Vertebrates 16, 257-284.

Tanaka Y, Ando T, Sawamura H (2018) A new species of Middle Miocene baleen whale from the Nupinai Group, Hikatagawa Formation of Hokkaido, Japan. PeerJ 6, e4934.

Thean T, Kardjilov N, Asher R (2017) Inner ear development in cetaceans. Journal of Anatomy 230, 249-261.

Tsai CH, Fordyce RE (2015) The Earliest Gulp-Feeding Mysticete (Cetacea: Mysticeti) from the Oligocene of New Zealand. Journal of Mammalian Evolution 22(4), 535-560.

Yamato M, Pyenson N (2015) Early development and orientation of the acoustic funnel provides insight into the evolution of sound reception pathways in Cetaceans. PloS One 10(3), $\mathrm{e} 0118582$.

Zimmer C (2011). Evolution: the triumph of an idea. New York: HarperCollins Publishers, Inc. 


\section{Supplementary Information}

362

363

364

365

366

367

368

369

370

371

372

373

374

375

376

377

378

379

380

381

382

383

384

385

386

387

388

389

390

391

392

393

394

395

396

397

398

399

\section{Institutional Abbreviations}

AGSO-CPC, Australian Geological Survey Organization, Symonston, Australia; AMP, Ashoro Museum of Paleontology, Hokkaido, Japan; BMNH, British Museum of Natural History, London, England; CCNHM, Cape Cod Museum of Natural History, Brewster, Massachusetts, United States of America; ChM-PV, The Charleston Museum, Charleston, South Carolina, United States of America; GMNH-PV, Gunma Museum of Natural History, Tomioka, Gunma, Japan; GNHM, Gamagori Natural History Museum, Gamagori, Japan; GSM, Georgia Southern Museum, Statesboro, Georgia, United States of America; GSP-UM, Geological Survey of Pakistan-University of Michigan collection, Islamabad, Pakistan; KMNH-VP, Kitakyushu Museum and Institute of Natural History, Fukuoka, Japan; LACM, Vertebrate Paleontology Collection, Natural History Museum of Los Angeles County, Los Angeles, California, United States of America; MAUL, Museo dell'Ambiente, Università di Lecce, Lecce, Italy; MNHN, Muséum National d'Histoire Naturelle, Paris, France; MO, Montañita/Olón collection, Universidad Estatal Peninsula de Santa Elena, La Libertad, Ecuador; MSM, Museum Sønderjylland, Department Natural History and Palaeontology, Gram, Denmark; MUEcSj, Museum of Natural History, Autonomous University of Baja California Sur, La Paz, Baja California Sur, México; MUSM, Museo de Historia Natural, Universidad Nacional Mayor de San Marco, Lima, Peru; NHG, Natuurhistorische collectie van het Zeeuws Genootschap der Wetenschappen, Middelburg, The Netherlands; NMB, Natuurmuseum Brabant, Tilburg, The Netherlands; NMNH-P, Academician V. A. Topachevsky Paleontological Museum of the National Museum of Natural History of the National Academy of Sciences of Ukraine, Kiev, Ukraine; NMR, Natuurhistorisch Museum Rotterdam, Rotterdam, the Netherlands; NMV-P, Museum Victoria Mammalogy (Melbourne), Melbourne, Australia; OU, Geology Museum, University of Otago, Dunedin, New Zealand; PIN, Borissiak Paleontological Institute, Russian Academy of Sciences, Moscow, Russia; SAE, Museo Civico di Storia Naturale di Verona, Verona, Italy; SC, South Carolina State Museum, Columbia, South Carolina, United States of America; SMAC, Sapporo Museum Activity Center, Sapporo, Hokkaido, Japan; TNU, Department of Zoology, Taurida National University, Simferopol, Ukraine; UMMP, University of Michigan, Museum of Paleontology, Ann Arbor, Michigan, United States of America; USNM, United States Smithsonian National Museum of Natural History, Washington D.C., United States of America; UWBM, Burke Museum, University of Washington, Seattle, Washington, United States of America.

\section{Data Availability}

The dataset is made available as an Excel file and provides measurements of bulla length, bulla width, and bizygomatic width.

\section{Supplementary Figures}


400 Supplementary Figure 1. The amalgamated phylogenetic tree used to compare stem cetaceans, mysticetes, and 401 odontocetes for the PIC. Branches and nodes are colored by their character trait value, bulla length: bizygomatic 402 width. 
404 Supplemental References

405

406

407

408

409

410

411

412

413

414

415

416

417

418

419

420

421

422

423

424

425

426

427

428

429

430

431

432

433

434

435

Albright, LB, Sanders, AE, Geisler, JH (2018) An unexpectedly derived odontocete from the Ashley Formation (upper Rupelian) of South Carolina, U.S.A. Journal of Vertebrate Paleontology 38(4), e1482555.

Bianucci, G (2005) Arimidelphis sorbinii a new small killer whale-like dolphin from the Pliocene of Marecchia River (Central eastern Italy) and a phylogenetic analysis of the Orcininae (Cetacea: Odontoceti). Rivista Italiana di Paleontologia e Stratigrafia 111(2), 329-344.

Bianucci, G, Lambert, O, Post, K (2010) High concentration of long-snouted beaked whales (Genus Messapicetus) from the Miocene of Peru. Palaeontology 53(5), 1077-1098.

Bianucci, G, Landini, W (2006) Killer sperm whale: a new basal physeteroid (Mammalia, Cetacea) from the Late Miocene of Italy. Zoological Journal of the Linnaean Society 148, 103131.

Bisconti, M (2005) Skull morphology and phylogenetic relationships of a new diminutive balaenid from the lower Pliocene of Belgium. Palaeontology 48(4), 793-816.

Boessenecker RW, Fordyce RE (2015) A new genus and species of eomysticetid (Cetacea: Mysticeti) and a reinterpretation of 'Mauicetus' lophocephalus Marples, 1956: Transitional baleen whales from the upper Oligocene of New Zealand. Zoological Journal of the Linnean Society 175(3).

Boessenecker RW, Fordyce, RE (2014) A new eomysticetid (Mammalia: Cetacea) from the Late Oligocene of New Zealand and re-evaluation of 'Mauicetus' waitakiensis. Papers in Palaeontology 1(2).

Boessenecker RW, Fordyce, RE (2015) Anatomy, feeding ecology, and ontogeny of a transitional baleen whale: a new genus and species of Eomysticetidae (Mammalia: Cetacea) from the Oligocene of New Zealand. PeerJ 3, e1129.

Bosselaers M (2010) A new fossil rorqual (Mammalia, Cetacea, Balaenopteridae) from the Early Pliocene of the North Sea, with a review of the rorqual species described by Owen and Van Beneden. Geodiversitas 36, 331-363.

Churchill M, Martinez-Caceres M, de Muizon C, Mnieckowski J, Geisler JH (2016). The origin of high-frequency hearing in whales. Current Biology 26(16), 2144-2149.

de Muizon C, Bianucci G, Martinez-Caceres M, Lambert O (2019) Mystacodon selenensis, the earliest known toothed mysticete (Cetacea, Mammalia) from the late Eocene of Peru: anatomy, phylogeny, and feeding adaptations. Geodiversitas 41(11), 401-499. 
436 Fitzgerald, EM (2006) A bizarre new toothed mysticete (Cetacea) from Australia and the early 437 evolution of baleen whales. Proceedings of the Royal Society 273, 2955-2963.

438 Fordyce RE (1994) Waipatia maerewhenua, New Genus and New Species, Waipatiidae, New 439 Family, an archaic late Oligocene dolphin (Cetacea: Odontoceti: Platanistoidea) from New 440 Zealand. Contributions in Marine Mammal Paleontology Honoring Frank C. Whitmore Jr., 441 Proceedings of the San Diego Society of Natural History 29, 147-176.

442 Fordyce RE, Quilty PG, Daniels J (2002) Australodelphis mirus, a bizarre new toothless 443 ziphiid-like fossil dolphin (Cetacea: Delphinidae) from the Pliocene of Vestfold Hills, East 444 Antarctica. Antarctic Science 14(1), 37-54.

445

446

447

448

449

450

451

452

453

454

455

456

457

458

459

460

461

462

463

464

465

466

467

Geisler JH, Boessenecker RW, Brown M, Beatty BL (2017) The origin of filter feeding in whales. Current Biology 27(13), 2036-2042.e2.

Geisler JH, Sanders AE, Luo Z (2005) A new protocetid whale (Cetacea: Archaeoceti) from the late middle Eocene of South Carolina. American Museum Novitates 3480, 1-65.

Gibson ML, Mnieckowski J, Geisler JH (2019) Tupelocetus palmeri, a new species of protocetid whale (Mammalia, Cetacea) from the middle Eocene of South Carolina. Journal of Vertebrate Paleontology 38(6), e1555165.

Gingerich PD, Arif M, Clyde WC (1995) New archaeocetes (Mammalia, Cetacea) from the Middle Eocene Domanda Formation of the Sulaiman Range, Punjab (Pakistan). Contributions from the Museum of Paleontology, University of Michigan 29(11), 291-330.

Gingerich PD, Russell DE (1981) Pakicetus inachus, a new archaeocete (Mammalia, Cetacea) from the early-middle Eocene Kuldana Formation of Kohat (Pakistan). Contributions from the Museum of Paleontology, University of Michigan 25(11), 235-246.

Gingerich PD, Ul-Haq M, Khan IH, Zalmout IS (2001) Eocene stratrigraphy and archaeocete whales (Mammalia, Cetacea) of Drug Lahar in the eastern Sulaiman range, Balochistan (Pakistan). Contributions from the Museum of Paleontology, University of Michigan 30(11), 269319.

Goldin P, Startsev D (2014) Brandtocetus, a new genus of baleen whales (Cetacea, Cetotheriidae) from the late Miocene of Crimea, Ukraine. Journal of Vertebrate Paleontology 34(2), 419-433.

Kellogg R (1924) Description of a new genus and species of whalebone whale from the Calvert Cliffs, Maryland. Proceedings of the United States National Museum 63(15), 1-14.

Kimura T, Hasegawa Y (2019) A new species of Kentriodon (Cetacea, Odontoceti, 
468 Kentriodontidae) from the Miocene of Japan. Journal of Vertebrate Paleontology 39(1), 469 e1566739.

470 Lambert $\mathbf{O}$ (2009) A new beaked whale (Odontoceti, Ziphiidae) from the middle Miocene of 471 Peru. Journal of Vertebrate Paleontology 29(3), 910-922.

472 Lambert O, Bianucci G, Urbina M, Geisler JH (2017) A new inioid (Cetacea, Odontoceti, 473 Delphinida) from the Miocene of Peru and the origin of modern dolphin and porpoise families. 474 Zoological Journal of the Linnean Society 179(4), 919-946.

475 Lambert O, de Muizon C, Bianucci G (2015) A new archaic homodont toothed cetacean 476 (Mammalia, Cetacea, Odontoceti) from the early Miocene of Peru. Geodiversitas 37(1), 79-108.

477 Martínez-Cáceres M, de Muizon C (2011) A new basilosaurid (Cetacea, Pelagiceti) from the 478 Late Eocene to Early Oligocene Otuma Formation of Peru. Comptes Rendus Palevol 10, 517479526.

480 Marx FG, Bosselaers MEJ, Louwye S (2016). A new species of Metopocetus (Cetacea, 481 Mysticeti, Cetotheriidae) from the Late Miocene of the Netherlands. PeerJ 4, e1572.

482 Marx FG, Kohno N (2016) A new Miocene baleen whale from the Peruvian desert. Royal 483 Society Open Science 3(10), 160542.

484 Marx FG, Lambert O, de Muizon, C (2017) A new Miocene baleen whale from Peru deciphers 485 the dawn of cetotheriids. Royal Society Open Science 4, 170560.

486 Marx FG, Post K, Bosselaers M, Munsterman DK (2019) A large Late Miocene cetotheriid 487 (Cetacea, Mysticeti) from the Netherlands clarifies the status of Tranatocetidae. PeerJ 7, e6426.

488 Marx FG, Tsai CH, Fordyce RE (2015) A new Early Oligocene toothed 'baleen' whale 489 (Mysticeti: Aetiocetidae) from western North America: one of the oldest and the smallest. Royal 490 Society Open Science 2(12), 150476.

491 Peredo C, Uhen MD, Nelson MD (2018) A new kentriodontid (Cetacea: Odontoceti) from the 492 early Miocene Astoria Formation and a revision of the stem delphinidan family Kentriodontidae. 493 Journal of Vertebrate Paleontology 38(2), e1411357.

494 Peredo CM, Pyenson ND (2018) Salishicetus meadi, a new aetiocetid from the late Oligocene 495 of Washington State and implications for feeding transitions in early mysticete evolution. Royal 496 Society Open Science 5, 172336.

497 Peredo CM, Uhen MD (2016) A new basal chaeomysticete (Mammalia: Cetacea) from the Late 498 Oligocene Pysht Formation of Washington, USA. Papers in Palaeontology 2(4), 533-554. 
499

500

501

502

503

504

505

506

507

508

509

510

511

512

513

514

515

516

517

518

Solis-Añorve A, González-Barba G, Hernández-Rivera R (2019) Description of a new toothed mysticete from the Late Oligocene of San Juan de La Costa, B.C.S., México. Journal of South American Earth Science 89, 337-346.

Steeman, ME (2009) A new baleen whale from the Late Miocene of Denmark and early mysticete hearing. Palaeontology 52(5), 1169-1190.

Tanaka Y, Abella J, Aguirre-Ferñ̃ndez G, Gregori M, Fordyce RE (2017) A new tropical Oligocene dolphin from MontanI fita/Ol $\tilde{A}^{3}$, Santa Elena, Ecuador. PLoS One 12(12), e0188380.

Tanaka Y, Ando T, Sawamura H (2018) A new species of Middle Miocene baleen whale from the Nupinai Group, Hikatagawa Formation of Hokkaido, Japan. PeerJ 6, e4934.

Tanaka Y, Fordyce RE (2015) A new Oligo-Miocene dolphin from New Zealand: Otekaikea huata expands diversity of the early Platanistoidea. Palaeontologia Electronica 18.2.23A, 1-71.

Tanaka Y, Fordyce RE (2016) Awamokoa tokarahi, a new basal dolphin in the Platanistoidea (late Oligocene, New Zealand). Journal of Systematic Palaeontology 15(5), 365-386.

Tarasenko KK, Lopatin AV (2012) New baleen whale genera (Cetacea, Mammalia) from the miocene of the northern caucasus and ciscaucasia: 1. Kurdalagonus gen. nov. from the middlelate Sarmatian of Adygea. Palaeontological Journal 46(6), 620-629.

Tsai CH, Fordyce RE (2015) The Earliest Gulp-Feeding Mysticete (Cetacea: Mysticeti) from the Oligocene of New Zealand. Journal of Mammalian Evolution 22, 535-560.

Vélez-Juarbe J (2017) A new stem odontocete from the late Oligocene Pysht Formation in Washington State, U.S.A. Journal of Vertebrate Paleontology 37(5), e1366916. 


\section{Figure 1}

Figure 1. 3D models of sample cetacean skulls illustrating the measurements collected for this study

including (A) a stem cetacean (Zygorhiza, USNM PAL 11962), (B) a mysticete (Balaenoptera, USNM VZ 593554), and (C) an odontocete (Tursiops USNM VZ 550969). Specimens are scaled to the same condylobasal length. BZW: Bizygomatic width, measured as the maximum distance across the zygomatic processes of the squamosals or estimated by doubling the measurement to the midline. BL: tympanic bulla length measured along its longest anteroposterior axis following the orientation guidelines of Mead and Fordyce (2009). BW: tympanic bulla width measured along its widest transverse axis following the orientation guidelines of Mead and Fordyce (2009). 
A. Zygorhiza

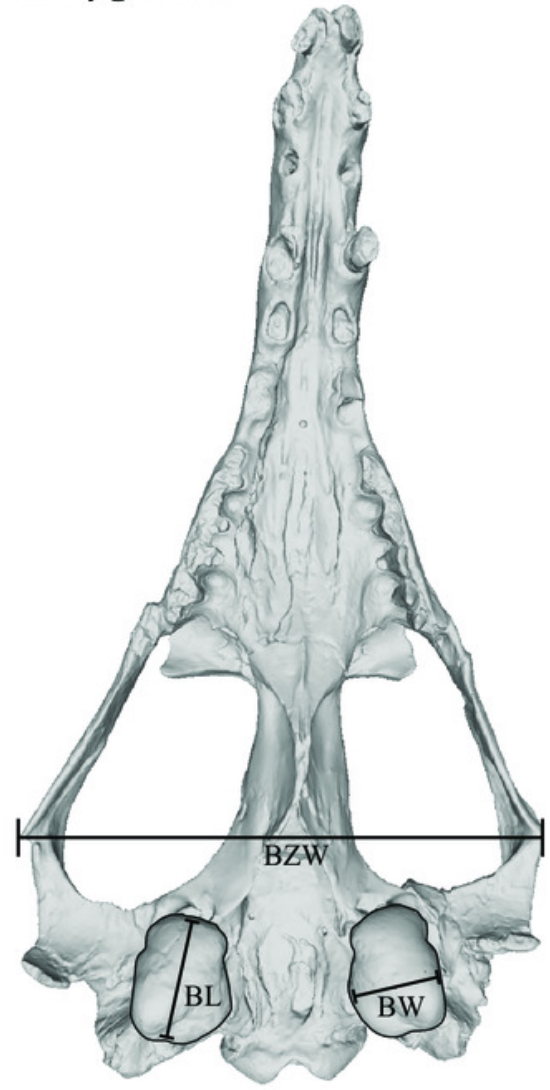

\section{B. Balaenoptera}

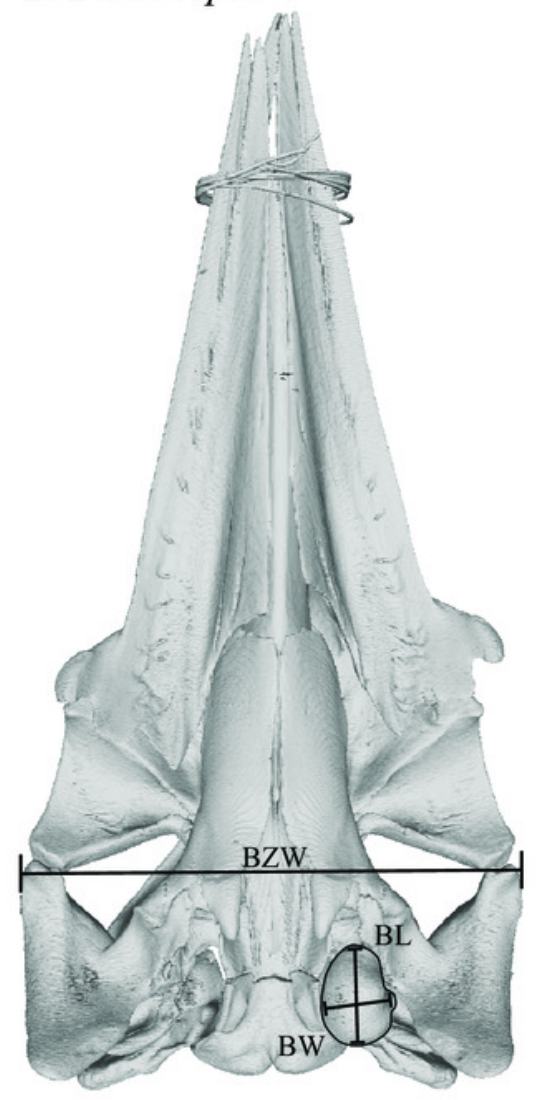

C. Tursiops

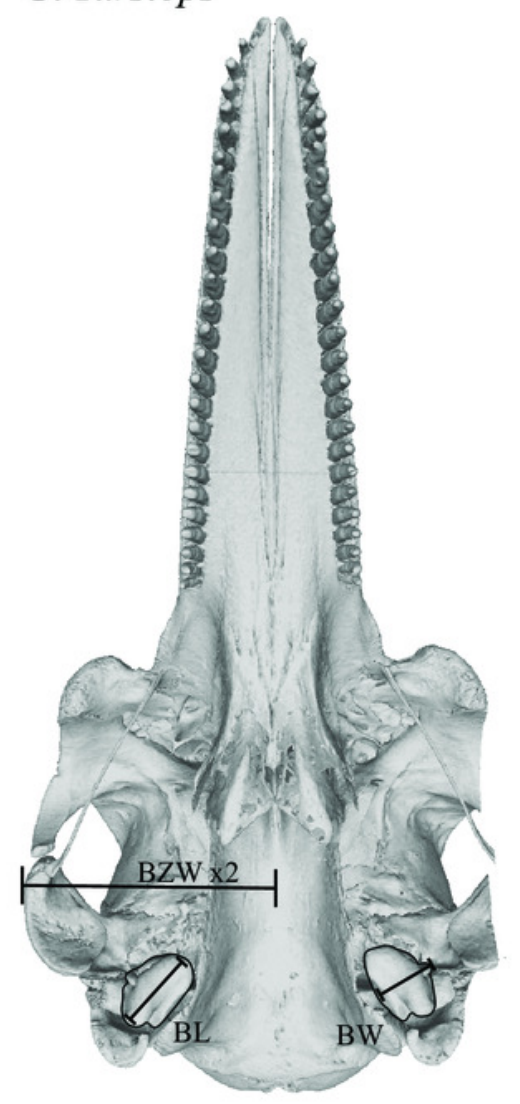


Figure 2

Figure 2. Log-transformed bivariate plot demonstrating allometric changes in bulla size and bizygomatic width:

A. Tympanic bulla length versus bizygomatic width. B. Tympanic bulla width versus bizygomatic width. Black dots represent specimens from the amalgamate dataset. Colored lines represent linear regressions. See text for statistical results.

A.

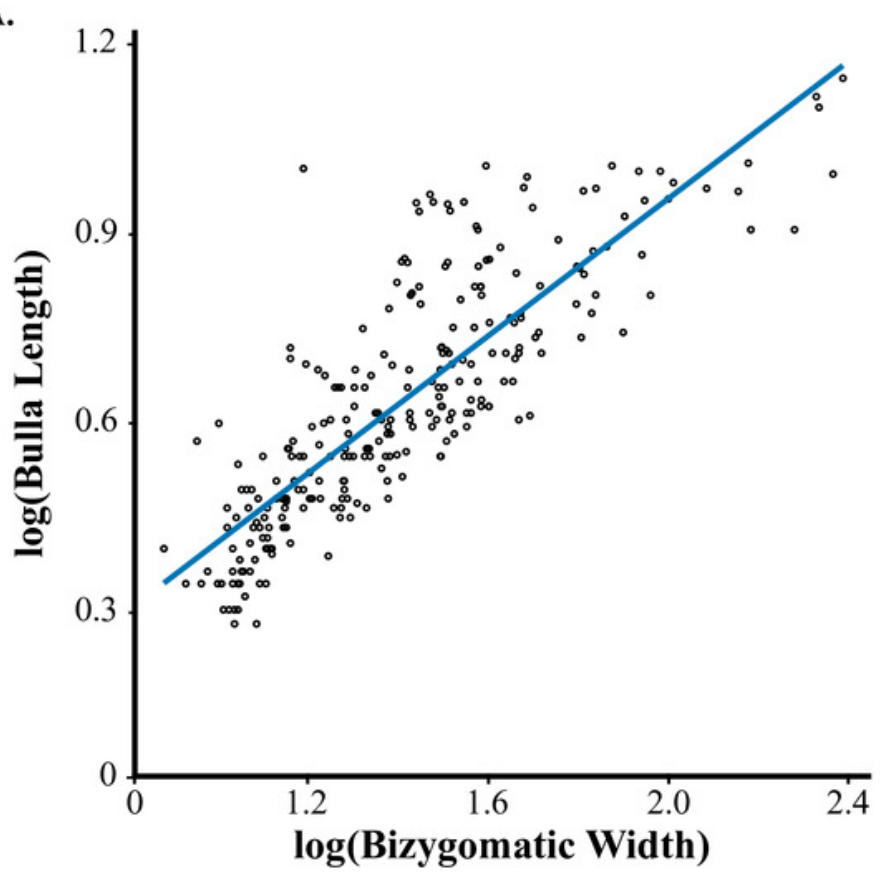

B.

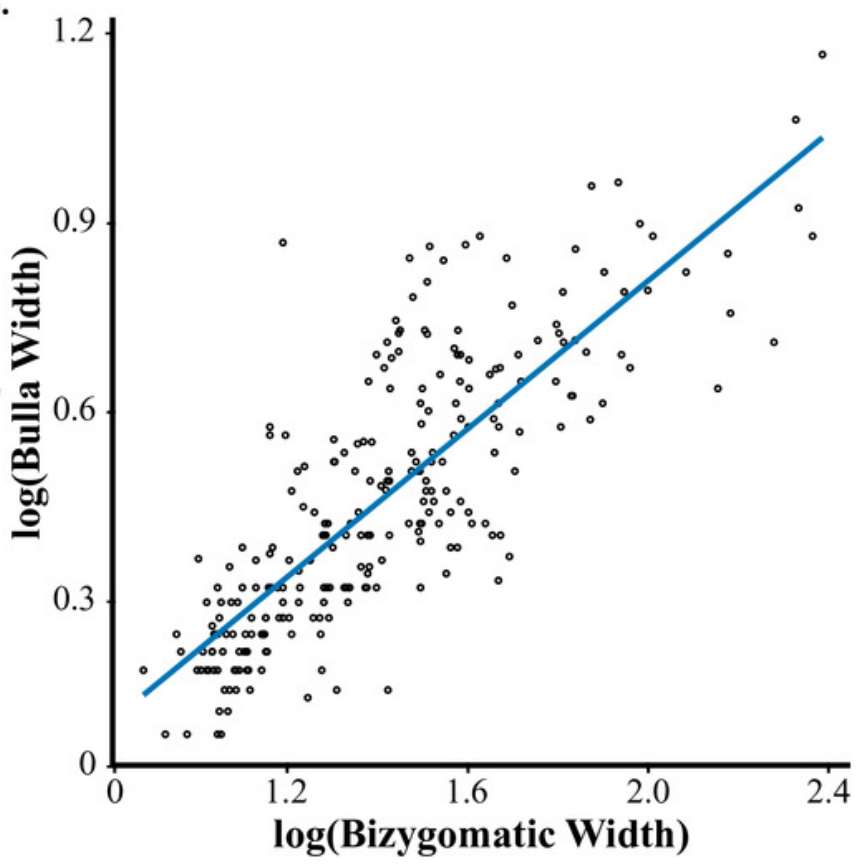


Figure 3

Figure 3. Allometric relationships of stem cetaceans, odontocetes, and mysticetes:

A. Tympanic bulla length (BL) versus bizygomatic width (BZW). B. Tympanic bulla width (BW) versus bizygomatic width (BZW). Green circles represent stem cetaceans, red correspond with odontocetes, and blue indicate mysticetes. Colored lines represent linear regressions by group.

A.

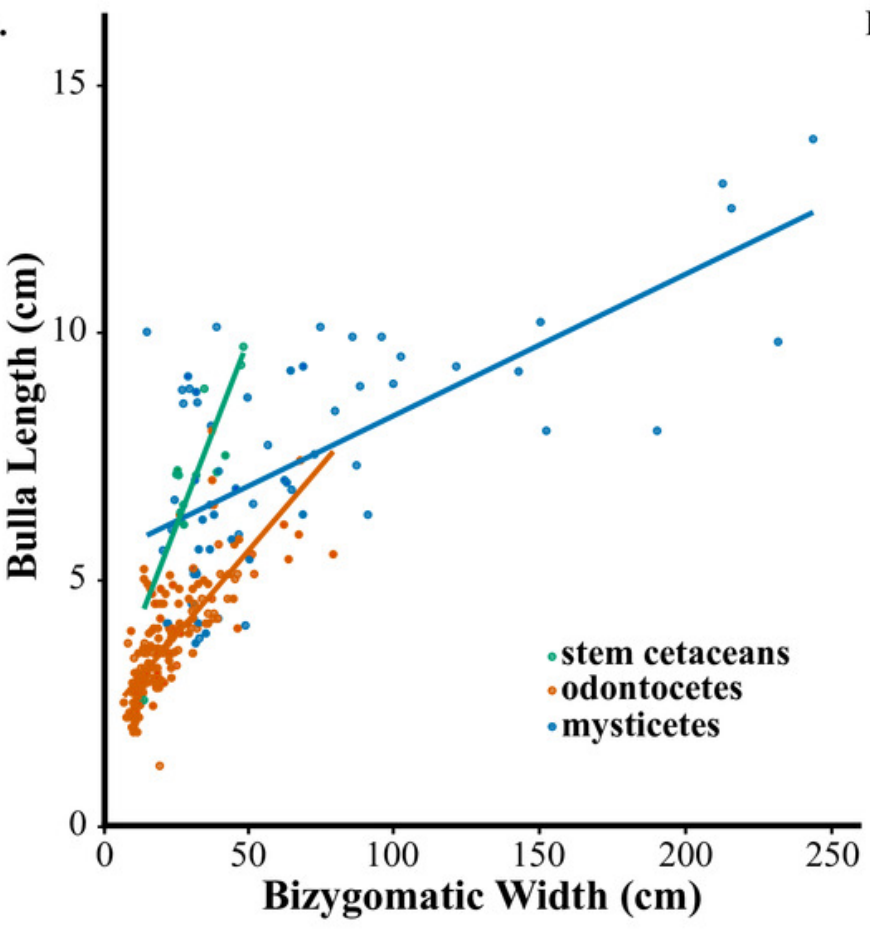

B.

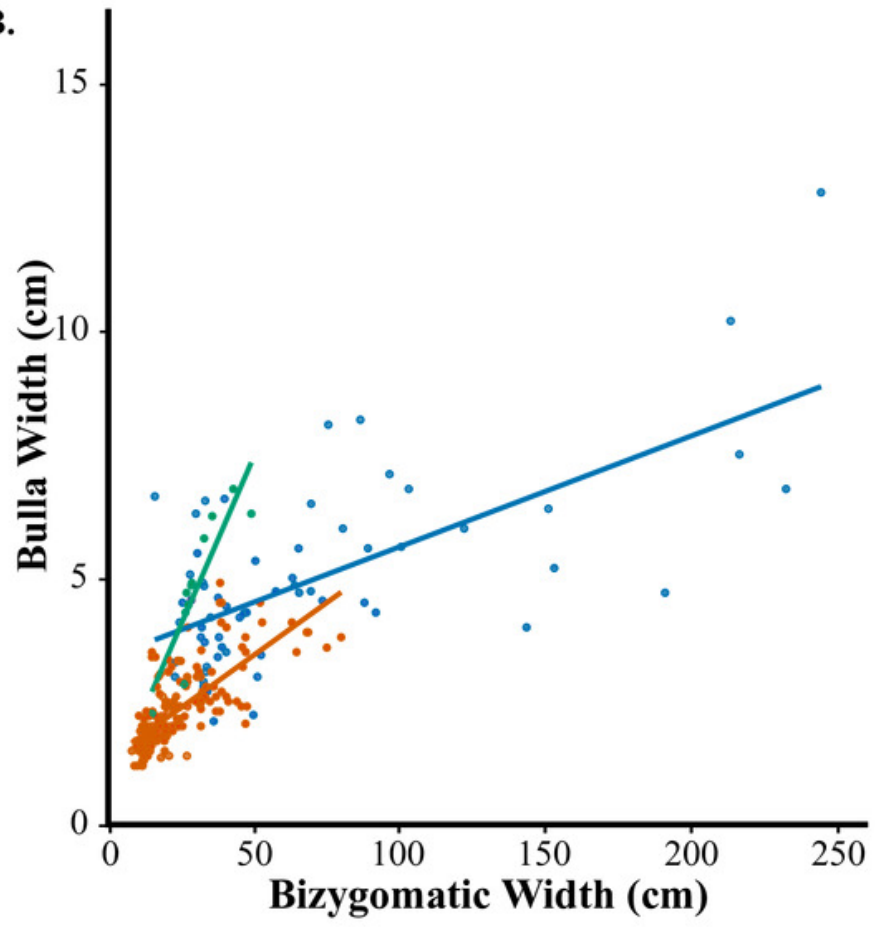

